\title{
Cytotoxicity and Induction of Inflammation by Pepsin in Acid in Bronchial Epithelial Cells
}

\author{
Erik Bathoorn, ${ }^{1,2}$ Paul Daly, ${ }^{1}$ Birgit Gaiser, ${ }^{1}$ Karl Sternad, ${ }^{1}$ Craig Poland, ${ }^{1}$ William MacNee, ${ }^{1}$ \\ and Ellen M. Drost ${ }^{1}$ \\ ${ }^{1}$ ELEGI, Colt Research Laboratories, MRC Centre for Inflammation Research, Queen's Medical Research Institute, \\ University of Edinburgh, Edinburgh EH 16 4TJ, UK \\ ${ }^{2}$ Department of Medical Microbiology, University Medical Center Utrecht, 3508 Utrecht, The Netherlands
}

Correspondence should be addressed to Erik Bathoorn, ebathoorn@gmail.com

Received 23 February 2011; Revised 17 May 2011; Accepted 20 May 2011

Academic Editor: Jean-Marc Cavaillon

Copyright (c) 2011 Erik Bathoorn et al. This is an open access article distributed under the Creative Commons Attribution License, which permits unrestricted use, distribution, and reproduction in any medium, provided the original work is properly cited.

\begin{abstract}
Introduction. Gastroesophageal reflux has been associated with chronic inflammatory diseases and may be a cause of airway remodelling. Aspiration of gastric fluids may cause damage to airway epithelial cells, not only because acidity is toxic to bronchial epithelial cells, but also since it contains digestive enzymes, such as pepsin. Aim. To study whether pepsin enhances cytotoxicity and inflammation in airway epithelial cells, and whether this is $\mathrm{pH}$-dependent. Methods. Human bronchial epithelial cells were exposed to increasing pepsin concentrations in varying acidic milieus, and cell proliferation and cytokine release were assessed. Results. Cell survival was decreased by pepsin exposure depending on its concentration $(F=17.4)$ and $\mathrm{pH}$ level of the medium $(F=6.5)($ both $P<0.01)$. Pepsin-induced interleukin-8 release was greater at lower $\mathrm{pH}(F=5.1 ; P<0.01)$. Interleukin-6 induction by pepsin was greater at $\mathrm{pH} 1.5$ compared to $\mathrm{pH} 2.5$ (mean difference $434 \% ; P=0.03$ ). Conclusion. Pepsin is cytotoxic to bronchial epithelial cells and induces inflammation in addition to acid alone, dependent on the level of acidity. Future studies should assess whether chronic aspiration causes airway remodelling in chronic inflammatory lung diseases.
\end{abstract}

\section{Introduction}

Aspiration of gastric fluids damages airway epithelial cells [1] due to the toxicity of its low $\mathrm{pH}$ [2]. Several in vivo and in vitro models have assessed the effect of acid aspiration on lung injury and inflammation, using a hydrochloric acid solution with a $\mathrm{pH}$ ranging from 1 to 1.5 [2-5]. In addition, gastric particles have been found to contribute to lung injury [6]. Previous in vivo and in vitro studies have shown that acid aspiration causes an IL- 6 and IL- 8 mediated neutrophil influx into the lungs $[2,3,7,8]$. A correlation between acid aspiration, increased IL-8 levels, and airway neutrophil counts has been found in asthma patients [9]. However, the acidity of gastric fluids might not be the only cause of damage and inflammatory response. Digestive enzymes such as pepsin might be an important factor as well.

Pepsin is stored as inactive pepsinogen in the chief cells of the gastric mucosa. It is a protease involved in the digestion of food, and its activity is acid-dependent. The conversion of pepsinogen to pepsin in the stomach starts slowly at $\mathrm{pH} 6$ and reaches optimal activity between $\mathrm{pH} 1.5$ to 2.5 . Above $\mathrm{pH} 6.8$, pepsin becomes inactive and above $\mathrm{pH} 7.5$ it is fully inactive and irreversibly denatured [10]. In human gastric fluid, the $\mathrm{pH}$ varies from 1.5 to 3 , which agrees with pepsin's activity optimum, and the concentration of pepsin varies from 0.5 to $1 \mathrm{mg} / \mathrm{mL}[11]$.

In recent years, pepsin has become an important and reliable biomarker for gastric aspiration [12-14], and has been associated with gastroesophageal reflux disease, lung rejection after transplantation, and bronchopulmonary dysplasia in children $[15,16]$. Experimental studies are needed to investigate whether pepsin is solely a marker of aspiration, or that these associations are partly caused by the pathological actions of pepsin. The combination of protein breakdown by pepsin and acid damage might result in an amplification of cell and tissue damage. Pepsin in acid has been shown to damage the esophageal tissue of rabbits, more so than acid alone [17]. The cytotoxicity and inflammation caused by a 
combination of acid and pepsin on airway epithelium has, until now, not been investigated.

To assess the additional effect of pepsin in inducing inflammation and cytotoxicity to airway cells, we briefly exposed bronchial epithelial cells to various $\mathrm{pH}$ levels with and without pepsin. We hypothesised that pepsin concentrations at a lower $\mathrm{pH}$ would result in increased cytotoxicity and induce proinflammatory cytokine release.

\section{Methods}

All reagents were obtained from Sigma-Aldrich, United Kingdom unless otherwise stated.

2.1. Cell Culture. Human bronchial epithelial cells (16-HBE, an SV-40 transformed cell-line) were maintained in continuous culture in Dulbecco's Modified Eagle's Medium supplemented with $10 \%$ heat-inactivated fetal bovine serum, $2 \mathrm{mM}$ glutamate, and penicillin $(100 \mathrm{IU} / \mathrm{mL}) /$ streptomycin $(100 \mu \mathrm{g} / \mathrm{mL})$. Cells were grown to confluency at $37^{\circ} \mathrm{C}$ in a humidified atmosphere containing $5 \% \mathrm{CO}_{2}$, washed with $\mathrm{Ca}^{2+} / \mathrm{Mg}^{2+}$-free phosphate-buffered saline (PBS-CMF), harvested with Trypsin-EDTA, and passaged.

The cells were seeded at a density of 60,000 per well in 24-well culture plates, and grown until approximately $80 \%$ confluent in complete media.

2.2. Experimental Model of Gastric Fluid Aspiration. $0.01 \mathrm{M}$ hydrochloric acid $(26 \mathrm{~mL}, 13 \mathrm{~mL}$, and $10 \mathrm{~mL})$ was added to cell culture medium $(25 \mathrm{~mL})$ until $\mathrm{pH}$ was $1.5,2$, and 2.5 , respectively. Pepsin concentrations of 40, 20, 10, 5, 2.5, and $1.25 \mathrm{mg} / \mathrm{mL}$ in $0.9 \%$ sodium chloride were prepared. Cell media was discarded and the wells were washed with PBSCMF. One hundred $\mu \mathrm{L}$ of pepsin solution was added to $900 \mu \mathrm{L}$ of acidified culture medium in the wells, and cells were exposed for 5 minutes to pepsin in each of the combinations of acidified culture medium, resulting in final pepsin concentrations of $4,2,1,0.5,0.25$, and $0.125 \mathrm{mg} / \mathrm{mL}$. Exposure medium was removed and cells were incubated for 20 hours in culture medium. Medium was centrifuged; cytotoxicity and cytokines were assessed in the supernatant. Each experiment was performed 3 times in duplicate.

2.3. Assessment of Cytotoxicity and Cytokine Release. Viability of cells was assessed by lactate dehydrogenase (LDH) (Roche Molecular Biochemicals, West Sussex, United Kingdom) release using pyruvic acid as a substrate and cell proliferation by Methylene Blue staining [18] by spectrometry. Interleukin-1 $\beta$ (IL-1 $\beta$ ), IL-5, IL-6, IL-8, IL-10, tumor necrosis factor- $\alpha$ (TNF- $\alpha)$, and vascular endothelial growth factor (VEGF) were measured by a cytometric bead array (BD Biosciences, Oxford, United Kingdom).

2.4. Statistics. Cell proliferation was expressed as an absorption percentage of the media control without pepsin with corresponding $\mathrm{pH}$; cytokine levels were corrected for cell proliferation and expressed as a percentage of the level of the corresponding $\mathrm{pH}$ without pepsin. Cytotoxicity measured

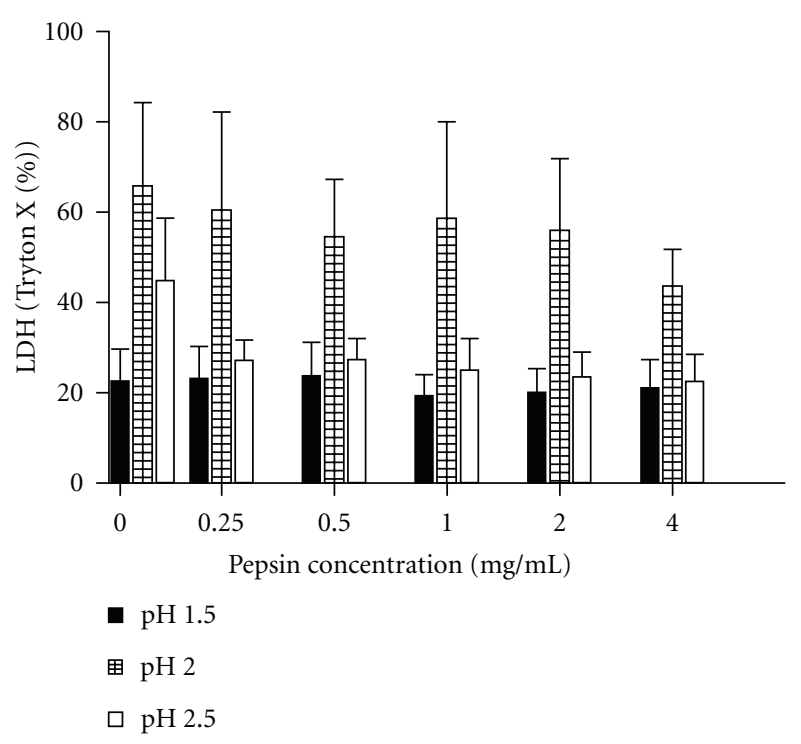

FIGURE 1: Exposure of cells for 5 minutes induced more cytotoxicity as measured by LDH after 20 hours incubation at $\mathrm{pH} 2.0$ (mean (SEM) $57 \% \pm 5.77 \%)$ compared to both $\mathrm{pH} 1.5$ and $\mathrm{pH} 2.5(22 \% \pm$ $2.17 \%$, and $28 \% \pm 2.81 \%$, resp., both $P<0.01)$. LDH release was $\mathrm{pH}$-dependent $(P<0.01)$. There was a trend for a pepsin effect $(P=$ 0.078 ), with lower $\mathrm{LDH}$ release with pepsin at all concentrations compared to no pepsin, independent of $\mathrm{pH}$ levels.

by $\mathrm{LDH}$ was expressed as an absorption percentage of exposure to $100 \%$ lysis (by Triton X). Cell proliferation, LDH cytotoxicity, and cytokine levels were analysed using a 2way ANOVA with pepsin concentration with $\mathrm{pH}$ as a fixed factor, and Tukey post-hoc testing. We considered $P<0.05$ as statistically significant. All data were analysed using the SPSS statistical package for Windows, version 12.0.1 (SPSS inc, Chicago, Illinois).

\section{Results}

3.1. Cytoxicity. Acidification of the cell culture induced cytotoxicity as measured by LDH significantly more at $\mathrm{pH} 2.0$ (mean (SEM) 57\% $\pm 5.77 \%$ ) compared to both $\mathrm{pH} 1.5$ and pH $2.5(22 \% \pm 2.17 \%$, and $28 \% \pm 2.81 \%$, resp., both $P<$ 0.01 , Figure 1). LDH-release therefore was $\mathrm{pH}$-dependent $(P<0.01)$. There was a trend for a pepsin effect $(P=0.078)$, with lower $\mathrm{LDH}$ release with pepsin at all concentrations compared to no pepsin, independent of $\mathrm{pH}$ levels.

The exposure of cells to media with $\mathrm{pH} 1.5$ for 5 minutes resulted in significantly less cell survival after 20 hours of incubation compared to $\mathrm{pH} 2.5$ (mean absorption 0.22 versus $0.57 ; P=0.03$, Figure 2 ). The addition of pepsin caused a decrease in cell survival, which was dependant on both pepsin and $\mathrm{pH}$ (both $P<0.01$, Figure 3 and supplemental Figure 1 in Supplementary Material online at doi: $10.4061 / 2011 / 569416)$. The effects of pepsin and acidified medium on cell survival were interactive $(P<0.01)$. Pepsin, resulted in lower cell survival compared to no pepsin at $\mathrm{pH}$ 1.5 at all concentrations tested $(P<0.01)$. At $\mathrm{pH} 2$ and $\mathrm{pH}$ 


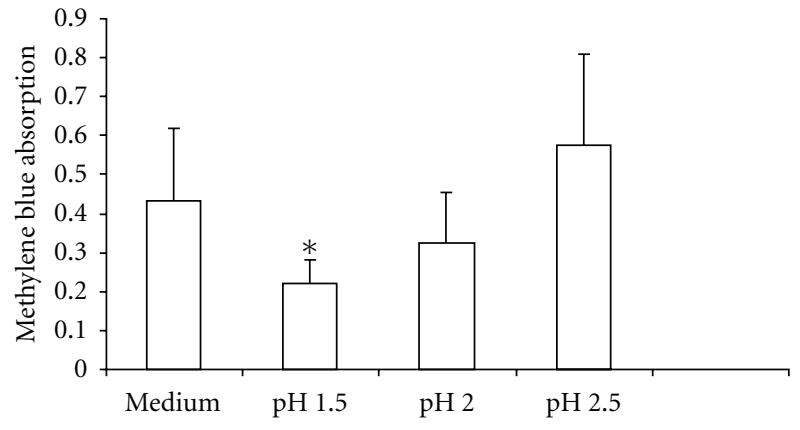

FIGURE 2: pH dependence of 16-HBE cell survival, as measured by methylene blue absorption. ${ }^{*}$ Exposure of cells to medium with $\mathrm{pH}$ 1.5 for 5 minutes resulted in significantly less cell proliferation after 20 hours of incubation compared to exposure to $\mathrm{pH} 2.5$ (mean absorption 0.22 versus $0.57 ; P=0.03, n=3$ ). $\mathrm{pH}$ of control medium was 7.9. Histograms represent the means and the bars the SEM.

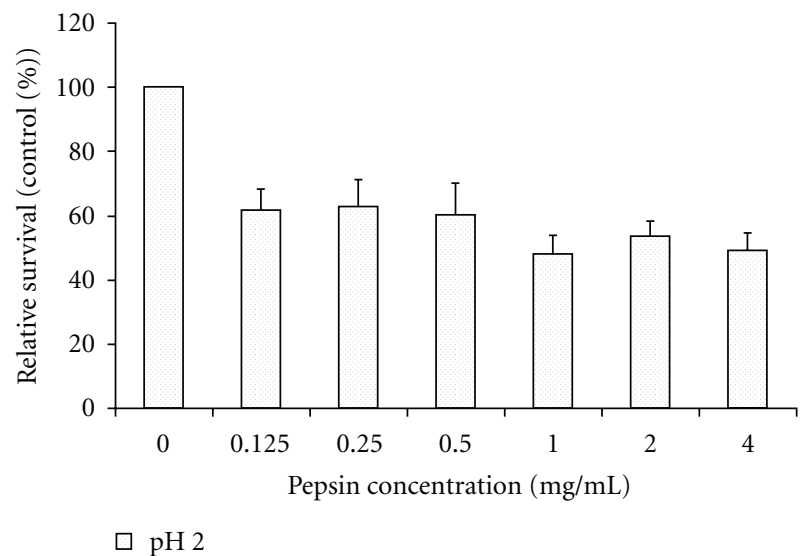

Figure 3: Effects of pepsin on cell survival, as measured by methylene blue absorption, and expressed as a \% of absorbance of treatment with the corresponding $\mathrm{pH}$ without pepsin (control). Pepsin induced a significant decrease in cell survival independent of $\mathrm{pH}(F=6.5 ; P<0.01)$. Data are expressed as means (histograms) and SEM (bars) for 3 replicates. See supplement Figure 1 for the effect of pepsin on cell survival of all the $\mathrm{pH}$ levels used in the statistical analysis.

2.5, there were trends towards lower cell survival with higher pepsin concentrations.

3.2. Cytokine Release. Figure 4 shows the effects of pepsin, dependent on dose and $\mathrm{pH}$ level, on IL-6 release. There was a trend towards more IL- 6 release induced by pepsin after exposure to media with a lower $\mathrm{pH}(P=0.09)$. Posthoc analysis showed that exposure at a $\mathrm{pH}$ of 1.5 resulted in a greater induction of IL- 6 release by pepsin compared to $\mathrm{pH} 2.5$ for all pepsin concentrations (mean difference 283\%; $P=0.03$ ) (see Figure 4 and supplement Figure 2).

The induction of IL- 8 release by pepsin was greater at lower $\mathrm{pH}$ levels $(P<0.01)$. Pepsin at a $\mathrm{pH}$ of 1.5 induced significantly more IL- 8 compared to $\mathrm{pH} 2.5$ for all pepsin concentrations (mean difference 221\%; $P<0.01$, Figure 5,

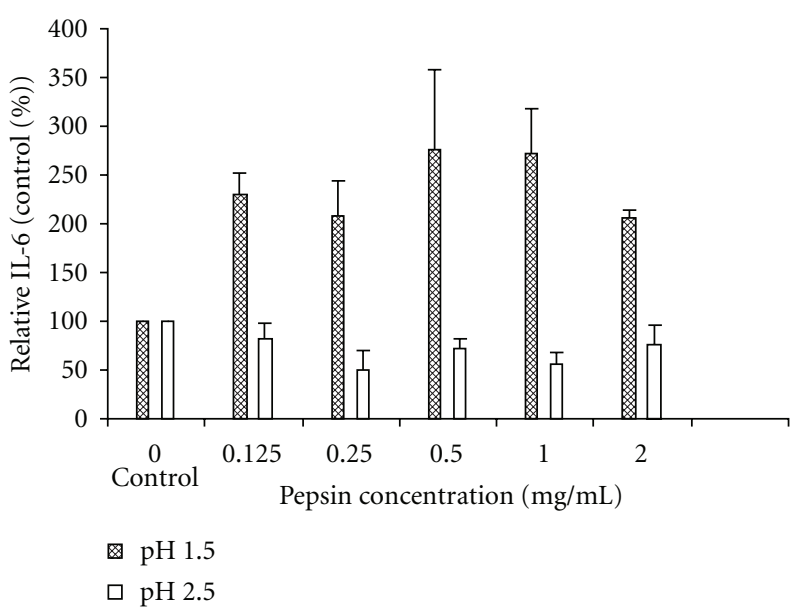

FIGURE 4: Interleukin-6 production by $16-\mathrm{HBE}$ cells, corrected for cell proliferation and expressed as a $\%$ of exposure with the corresponding $\mathrm{pH}$ without pepsin (control). Interleukin-6 release induced by pepsin is higher at $\mathrm{pH} 1.5$ compared to $\mathrm{pH} 2.5$ (mean difference 283\%; $P=0.03$ ). Data are expressed as means (histograms) and SEM (bars) for 3 replicates. See supplement Figure 2 for induction of IL-6 at all pepsin concentrations and $\mathrm{pH}$ levels used in the statistical analysis.

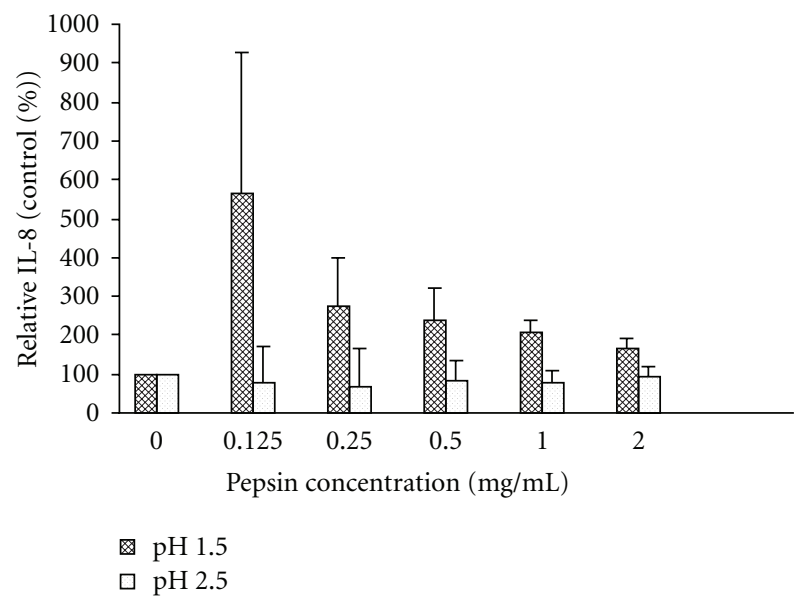

FIGURE 5: Interleukin-8 production by 16-HBE cells, corrected for cell proliferation and expressed as a \% of exposure with the corresponding $\mathrm{pH}$ without pepsin (control). Interleukin-8 release induced by pepsin is higher at $\mathrm{pH} 1.5$ compared to $\mathrm{pH} 2.5$ (mean difference $221 \%$; $P<0.01$ ). Data expressed as mean (histograms) and SEM (bars) for 3 replicates. See supplement Figure 3 for induction of IL- 8 at all pepsin concentrations and $\mathrm{pH}$ levels used in the statistical analysis.

and supplement Figure 3). We were unable to detect VEGF$\mathrm{B}$ with $\mathrm{pH} 1.5$ and $\mathrm{pH}$ 2. With $\mathrm{pH} 2.5$, there was no effect of pepsin on VEGF-B release. IL- $1 \beta$, IL-5, and TNF- $\alpha$ were not detected.

\section{Discussion}

We found that pepsin is cytotoxic and induces inflammation in bronchial epithelial cells. Pepsin-induced cytotoxicity to 
$16 \mathrm{HBE}$ cells is $\mathrm{pH}$-dependent, with the greatest effect seen at the lowest acidity. Likewise, pepsin-mediated IL-6 and IL-8 release is greatest in media with a lower $\mathrm{pH}$.

We assessed cell damage by both lactate dehydrogenase (LDH) release from airway epithelial cells that indicated disruption of the cell membrane and Methylene Blue staining of, predominantly, nucleic acids. Methylene Blue is generally used to measure cell proliferation, and also gives an indication of cell damage due to detachment. The LDH assay showed lower levels with more toxic concentrations of $\mathrm{pH}$ and pepsin. This is probably due to the removal of medium used during cell exposure before incubation, which resulted in removal of the $\mathrm{LDH}$ released in the first 5 minutes. Therefore, our study does not report an acute toxic effect at least as measured by LDH release.

A disadvantage of assessing cell number with Methylene Blue might be the loss of living cells when the exposure medium is exchanged for incubation medium: pepsin may destroy adhesion molecules, resulting in free floating live cells, which could be lost during the removal of the medium. Acid exposure makes the cells more susceptible, facilitating greater cell detachment by pepsin. To minimise loss of cells due to detachment, we did not wash the wells after exposure, but carefully removed the exposure medium. Nonetheless, it is quite possible that we lost live cells during this procedure. In vivo studies have found that destruction of junctional molecules by pepsin causes erosive lesions in the oesophageal epithelium, and similar lesions have been found in the airways due to gastric fluid aspiration [1, 17]. We did not determine, in our model, the number of cells that were lost due to detachment or due to cell death.

We used an experimental protocol that is very cytotoxic: we had to expose cells to low $\mathrm{pH}$ levels, since pepsin requires a $\mathrm{pH}$ of 3 or under to become activated [17]. Therefore, we corrected for cell number to analyse cytokine release. We assessed exposure times of 5 minutes and 1 hour, but found the 1 hour exposure time to be markedly toxic to the cells due to extended exposure to low $\mathrm{pH}$. Likewise, the cells were exposed in full media, containing physiologically relevant $10 \%$ serum, to offer some protection, since preliminary experiments (not shown) showed that the low $\mathrm{pH}$ and pepsin were very toxic. However, it should be noted that acidifying the medium with $\mathrm{HCl}$ to the various $\mathrm{pH}$ levels would have resulted in dilution of the medium causing changes in the osmolarity, as well as changes in the medium due to reaction of $\mathrm{HCl}$ with media components. Thus, we expressed the results of the effects of pepsin as a ratio to the medium of the corresponding $\mathrm{pH}$ without pepsin to correct for this bias.

Chronic aspiration has been associated with chronic inflammatory lung diseases. There are few data on the consequences of chronic aspiration. It is tempting to hypothesise that chronic aspiration leads to airway remodelling and the development of COPD, since recent reports suggest strong associations between COPD and gastroesophageal reflux disease [19-21]. Whether aspiration is the cause of this association is unknown. Our in vitro model shows that aspiration could lead to direct epithelial damage and the release of inflammatory mediators, involving at least the cytokines IL6 and IL-8. These cytokines are involved in recruitment of neutrophils, and induction of acute phase reactants, and are increased in sputum during COPD exacerbations [22]. Models of chronic aspiration are required to determine which consequences our acute observations have in the development of COPD. Since we found cytotoxic and pro-inflammatory effects of pepsin in addition to those caused by acids alone, future studies investigating the consequences of chronic aspiration should include pepsin in aspiration models. Future human studies should assess whether chronic aspiration causes airway remodelling.

\section{Abbreviations}

COPD: Chronic obstructive pulmonary disease

GER: Gastroesophageal reflux

HBE: Human bronchial epithelial cells

IL: Interleukin

PBS-CMF: $\mathrm{Ca}^{2+} / \mathrm{Mg}^{2+}$-free phosphate-buffered saline

TNF- $\alpha$ : Tumor necrosis factor- $\alpha$

VEGF: Vascular endothelial growth factor

LDH: $\quad$ Lactate dehydrogenase.

\section{Acknowledgment}

The authors would like to thank Shonna Johnston for performing the bead flow-cytometry, Dr Rodger Duffin for the 16-HBE cells, Huib Kerstjens for critical appraisal and support, and the European Respiratory Society, and Stichting Astma Bestrijding for their financial support. This paper was funded by Stichting Asthma Bestrijding, the Netherlands. Erik Bathoorn is the recipient of a European Respiratory Society Fellowship (no. 382).

\section{References}

[1] J. W. Wynne, R. Ramphal, and C. I. Hood, "Tracheal mucosal damage after aspiration. A scanning electron microscope study," American Review of Respiratory Disease, vol. 124, no. 6, pp. 728-732, 1981.

[2] C. Bonnans, K. Fukunaga, M. A. Levy, and B. D. Levy, "Lipoxin A4 regulates bronchial epithelial cell responses to acid injury," American Journal of Pathology, vol. 168, no. 4, pp. 1064-1072, 2006.

[3] B. Beck-Schimmer, D. S. Rosenberger, S. B. Neff et al., "Pulmonary aspiration: new therapeutic approaches in the experimental model," Anesthesiology, vol. 103, no. 3, pp. 556-566, 2005.

[4] N. D. Nader, B. A. Davidson, A. R. Tait, B. A. Holm, and P. R. Knight, "Serine antiproteinase administration preserves innate superoxide dismutase levels after acid aspiration and hyperoxia but does not decrease lung injury," Anesthesia and Analgesia, vol. 101, no. 1, pp. 213-219, 2005.

[5] T. Nagase, N. Uozumi, S. Ishii et al., "Acute lung injury by sepsis and acid aspiration: a key role for cytosolic phospholipase A2," Nature Immunology, vol. 1, no. 1, pp. 42-45, 2000.

[6] B. A. Davidson, P. R. Knight, Z. Wang et al., "Surfactant alterations in acute inflammatory lung injury from aspiration of acid and gastric particulates," American Journal of Physiology, vol. 288, no. 4, pp. L699-L708, 2005.

[7] T. P. Kennedy, K. J. Johnson, R. G. Kunkel, P. A. Ward, P. R. Knight, and J. S. Finch, "Acute acid aspiration lung injury in 
the rat: biphasic pathogenesis," Anesthesia and Analgesia, vol. 69, no. 1, pp. 87-92, 1989.

[8] H. G. Folkesson, M. A. Matthay, C. A. Hebert, and V. C. Broaddus, "Acid aspiration-induced lung injury in rabbits is mediated by interleukin- 8-dependent mechanisms," Journal of Clinical Investigation, vol. 96, no. 1, pp. 107-116, 1995.

[9] O. Sacco, M. Silvestri, F. Sabatini et al., "IL-8 and airway neutrophilia in children with gastroesophageal reflux and asthma-like symptoms," Respiratory medicine, vol. 100, no. 2, pp. 307-315, 2006.

[10] D. W. Piper and B. H. Fenton, "pH stability and activity curves of pepsin with special reference to their clinical importance," Gut, vol. 6, no. 5, pp. 506-508, 1965.

[11] K. K. Balan, A. T. Jones, N. B. Roberts, J. P. Pearson, M. Critchley, and S. A. Jenkins, "The effects of Helicobacter pylori colonization on gastric function and the incidence of portal hypertensive gastropathy in patients with cirrhosis of the liver," American Journal of Gastroenterology, vol. 91, no. 7, pp. 1400-1406, 1996.

[12] N. A. Metheny, Y. H. Chang, J. S. Ye et al., "Pepsin as a marker for pulmonary aspiration," American Journal of Critical Care, vol. 11, no. 2, pp. 150-154, 2002.

[13] S. Farrell, C. McMaster, D. Gibson, M. D. Shields, and W. A. McCallion, "Pepsin in bronchoalveolar lavage fluid: a specific and sensitive method of diagnosing gastro-oesophageal refluxrelated pulmonary aspiration," Journal of Pediatric Surgery, vol. 41, no. 2, pp. 289-293, 2006.

[14] S. Farhath, Z. H. Aghai, T. Nakhla et al., "Pepsin, a reliable marker of gastric aspiration, is frequently detected in tracheal aspirates from premature ventilated neonates: relationship with feeding and methylxanthine therapy," Journal of Pediatric Gastroenterology and Nutrition, vol. 43, no. 3, pp. 336-341, 2006.

[15] R. Stovold, I. A. Forrest, P. A. Corris et al., "Pepsin, a biomarker of gastric aspiration in lung allografts: a putative association with rejection," American Journal of Respiratory and Critical Care Medicine, vol. 175, no. 12, pp. 1298-1303, 2007.

[16] S. Farhath, Z. He, T. Nakhla et al., "Pepsin, a marker of gastric contents, is increased in tracheal aspirates from preterm infants who develop bronchopulmonary dysplasia," Pediatrics, vol. 121, no. 2, pp. e253-e259, 2008.

[17] N. A. Tobey, S. S. Hosseini, C. Caymaz-Bor, H. R. Wyatt, G. S. Orlando, and R. C. Orlando, "The role of pepsin in acid injury to esophageal epithelium," American Journal of Gastroenterology, vol. 96, no. 11, pp. 3062-3070, 2001.

[18] M. H. Oliver, N. K. Harrison, J. E. Bishop, P. J. Cole, and G. J. Laurent, "A rapid and convenient assay for counting cells cultured in microwell plates: application for assessment of growth factors," Journal of Cell Science, vol. 92, no. 3, pp. 513$518,1989$.

[19] C. Casanova, J. S. Baudet, M. del Valle Velasco et al., "Increased gastro-oesophageal reflux disease in patients with severe COPD," European Respiratory Journal, vol. 23, no. 6, pp. 841845, 2004.

[20] B. Mokhlesi, A. L. Morris, C. F. Huang, A. J. Curcio, T. A. Barrett, and D. W. Kamp, "Increased prevalence of gastroesophageal reflux symptoms in patients with COPD," Chest, vol. 119, no. 4, pp. 1043-1048, 2001.

[21] A. Ducolone, A. Vandevenne, H. Jouin et al., "Gastroesophageal reflux in patients with asthma and chronic bronchitis," Allergie et Immunologie, vol. 20, no. 6, pp. 218-225, 1988.

[22] E. Bathoorn, J. J. W. Liesker, D. S. Postma et al., "Change in inflammation in out-patient COPD patients from stable phase to a subsequent exacerbation," International Journal of COPD, vol. 4, no. 1, pp. 101-109, 2009. 


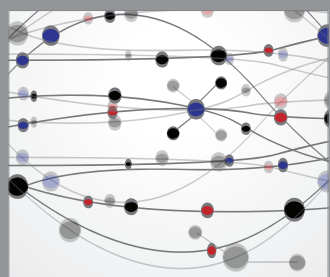

The Scientific World Journal
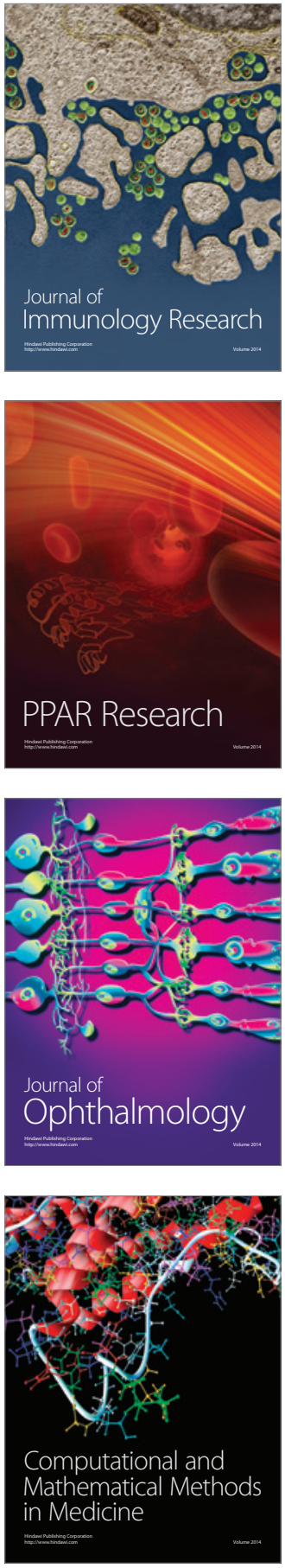

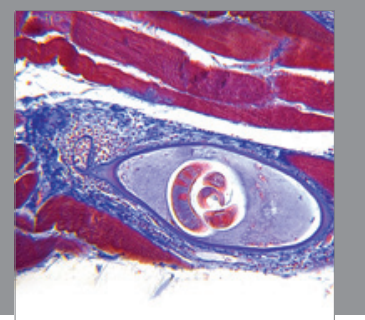

Gastroenterology

Research and Practice
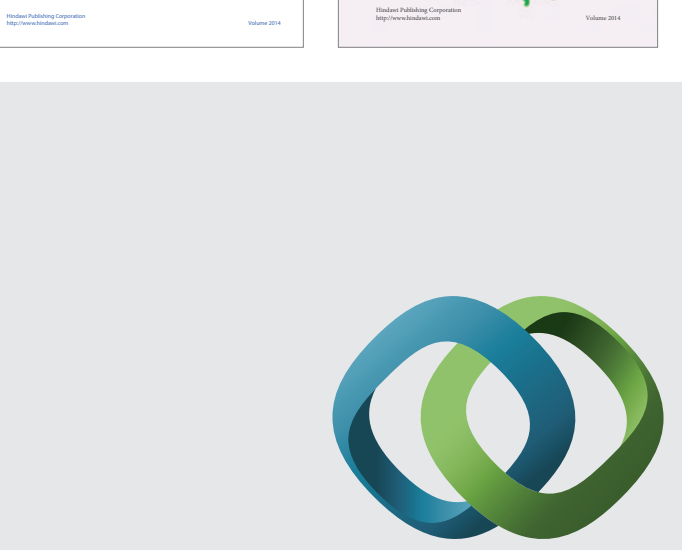

\section{Hindawi}

Submit your manuscripts at

http://www.hindawi.com
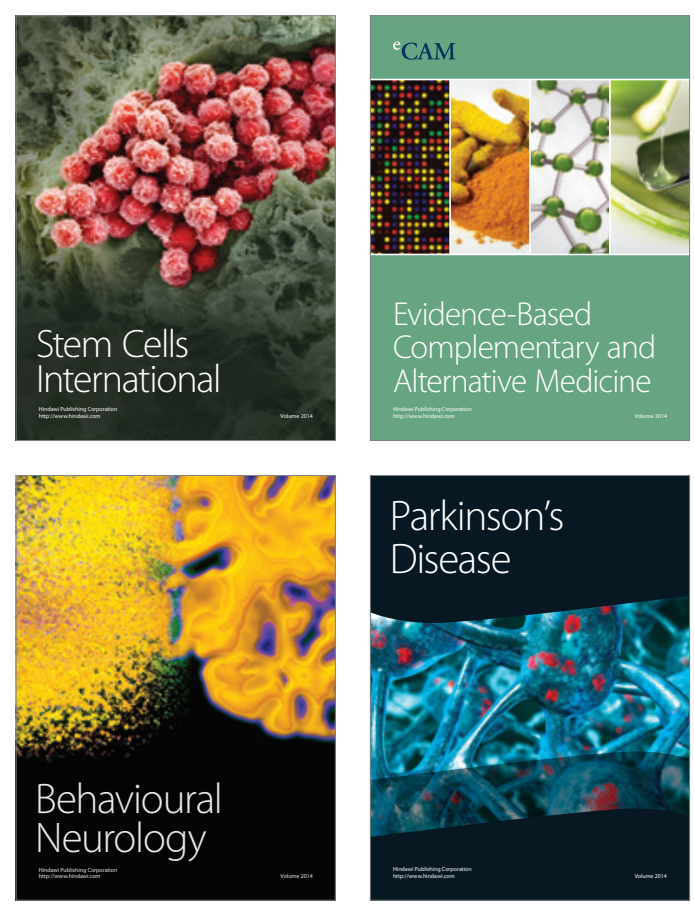

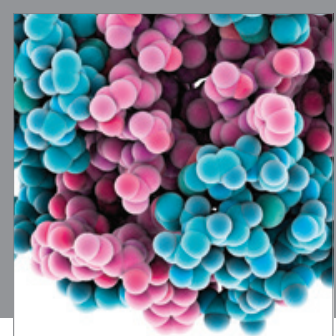

Journal of
Diabetes Research

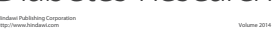

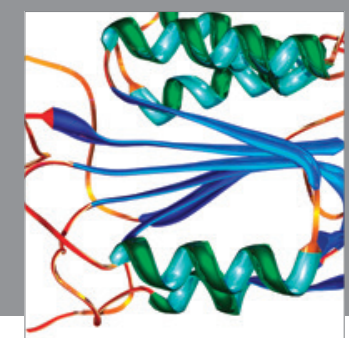

Disease Markers
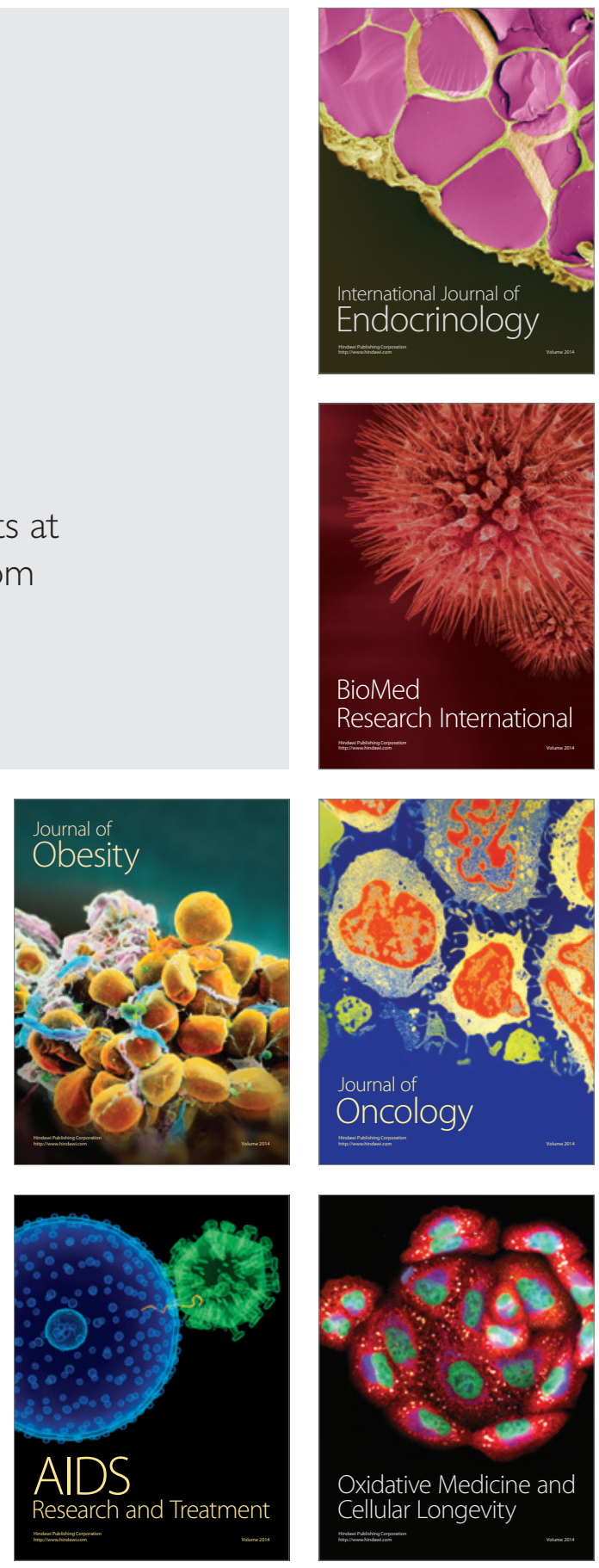